\title{
Atuação da enfermagem em Unidade de Terapia Intensiva em face da síndrome pós- parada cardíaca: uma revisão integrativa da literatura.
}

\author{
Nursing care in Intensive Care Unit in the face of post-cardliac arrest syndrome: an integrative
} review of the literature.

Cuidados de enfermería en la Unidad de Cuidados Intensivos ante el síndrome postparada cardíaca: una revisión bibliográfica integradora.

Mayara Cavalcante Rodrigues ORCID: https://orcid.org/0000-0003-4979-318X Universidade Potiguar, Brasil

E-mail: mayara10036@gmail.com

Renata Kely Pimentel da Cunha ORCID: https://orcid.org/0000-0003-4533-5851 Universidade Potiguar, Brasil E-mail: rekely@hotmail.com

Maria Letícia da Silva Viana ORCID: https://orcid.org/0000-0002-4926-3878 Centro Universitário Unifacex, Brasil

E-mail: marialeticiaviana16@gmail.com

José Lucas dos Santos Félix ORCID: https://orcid.org/0000-0003-0608-907X Universidade Potiguar, Brasil

E-mail: lucassantos92005613@gmail.com

Maria Renata da Silva Galvão ORCID: https://orcid.org/0000-0003-2880-8362 Universidade Potiguar, Brasil E-mail: renata-rn@hotmail.com

Vera Lúcia Morais da Silva ORCID: https://orcid.org/0000-0002-7675-1199 Universidade Potiguar, Brasil

E-mail: veraleite035@gmail.com

\section{Resumo}

Introdução: A Síndrome Pós-Parada Cardíaca (SPPC) caracteriza-se pela inflamação sistêmica, seguida de risco de falência de múltiplos órgãos, em decorrência do estresse oxidativo gerado após o período de isquemia. A enfermagem no manejo clínico da SPPC atua diretamente na identificação precoce e em condutas que resultem em circunstâncias de risco reduzido. Objetivo: Identificar, através da literatura, a atuação da Enfermagem intensivista frente aos sinais clínicos da SPPC. Metodologia: Revisão integrativa da literatura. Realizou-se a busca dos artigos por meio da Biblioteca Virtual de Saúde (BVS), na Base de Dados de Enfermagem (BDENF), Literatura Latino Americana e do Caribe em Ciências da Saúde (LILACS) e Medical Literature Review and Online Recovery System (MEDLINE). Resultados e Discussão: A enfermagem em UTI diante da SPPC, atua por intermédio de intervenções com o objetivo de alcançar a estabilização desse quadro clínico. Dessa forma, a educação continuada é uma ferramenta relevante na qualidade desse atendimento, pois faz-se necessário o conhecimento acerca do processo fisiopatológico e da adequada assistência. Conclusão: A atuação da enfermagem frente à SPPC e a destreza em seu manejo encontram limitações na deficiência de padronização e no estabelecimento de escores específicos para essa enfermidade e, o dimensionamento inadequado da equipe, colabora com a piora no prognóstico do paciente, pois um bom atendimento se baseia na tríade previsibilidade-assistência-equipe.

Palavras-chave: Enfermagem; Unidade de Terapia Intensiva; Parada cardíaca; Síndrome Pós-Parada Cardíaca; Enfermagem Centrada no Paciente.

\section{Abstract}

Introduction: The Post-Cardiac Arrest Syndrome (PCAS) is characterized by systemic inflammation, followed by risk of multiple organ failure, due to oxidative stress generated after the period of ischemia. Nursing in the clinical management of PPS acts directly in the early identification and conducts that result in reduced risk circumstances. Objective: To identify, through literature, the role of intensivist nursing in the clinical signs of PPSC. Methodology: 
Integrative literature review. Articles were searched using the Biblioteca Virtual de Saúde (BVS), Base de Dados de Enfermagem (BDENF), Latin American and Caribbean Literature on Health Sciences (LILACS) and Medical Literature Review and Online Recovery System (MEDLINE). Results and Discussion: ICU nursing, when facing PCAS, acts by means of interventions aiming at the stabilization of this clinical picture. Thus, continuing education is a relevant tool in the quality of this care, because it is necessary the knowledge about the pathophysiological process and the appropriate assistance. Conclusion: The nursing performance in PCAS and the skill in its management are limited by the lack of standardization and the establishment of specific scores for this disease, and the inadequate dimensioning of the team contributes to worsening the patient's prognosis, because good care is based on the triad predictabilityassistance-team.

Keywords: Nursing; Intensive Care Unit; Heart Failure; Post-Cardiac Arrest Syndrome; Patient-Centered Nursing.

\section{Resumen}

Introducción: El síndrome postparada cardíaca (SPPC) se caracteriza por la inflamación sistémica, seguida de riesgo de fallo orgánico múltiple, debido al estrés oxidativo generado tras el periodo de isquemia. La enfermería en el manejo clínico del SPPC actúa directamente en la identificación precoz y en las conductas que resultan en la reducción de las circunstancias de riesgo. Objetivo: Identificar, a través de la literatura, la actuación de la enfermería intensiva frente a los síntomas clínicos del SPPC. Metodología: Revisión integradora de la literatura. Los artículos se buscaron en la Biblioteca Virtual de Saúde (BVS), en la Base de Dados de Enfermagem (BDENF), en la Literatura Latinoamericana y del Caribe en Ciencias de la Salud (LILACS) y en el Medical Literature Review and Online Recovery System (MEDLINE). Resultados y Discusión: La enfermería de la UCI ante el SCP actúa a través de intervenciones encaminadas a conseguir la estabilización de este cuadro clínico. Así, la formación continua es una herramienta relevante en la calidad de esta atención, ya que es necesario el conocimiento del proceso fisiopatológico y la asistencia adecuada. Conclusión: La actuación de la enfermería frente a la SPPC y la destreza en su manejo encuentran limitaciones en la deficiencia de la preconización y en el establecimiento de escores específicos para esta enfermedad y, el dimensionamiento inadecuado del equipo, colabora con el deterioro del pronóstico del paciente, ya que una buena atención se basa en la tríada previsibilidad-asistencia-equipo.

Palabras clave: Enfermería; Unidad de Cuidados Intensivos; Insuficiencia Cardíaca; Síndrome de Parada Cardíaca; Enfermería centrada en el paciente.

\section{Introdução}

A Parada Cardiorrespiratória (PCR) é uma condição em que o coração se encontra impossibilitado de exercer sua função de bombear sangue e nutrientes para os órgãos do corpo humano, como cérebro, pulmões e rins, em virtude de uma parada súbita da bomba cardíaca, desencadeada por etiologia multifatorial. É uma emergência clínica grave que se faz necessário o atendimento imediato à vítima, a fim de minimizar o risco de falência múltipla dos órgãos devido ao déficit de oxigenação tissular. Os danos causados pela cessação do trabalho cardíaco têm consequências sistêmicas graves, podem ser irreversíveis e, inclusive, levar o paciente ao óbito (Beccaria et al., 2017).

A assistência às vítimas de PCR é realizado por meio da ressuscitação cardiopulmonar (RCP) que consiste em um conjunto de manobras realizadas pela equipe prestadora do atendimento ao paciente, associado ao uso de medicamentos, oferta de oxigênio e desfibrilação precoce, em conformidade com as diretrizes preconizadas pela American Heart Association (AHA) (Ferreira et al., 2018). Esse conjunto de ações interligadas visam manter, artificialmente, a perfusão e a oxigenação tecidual e, de forma precípua, restabelecer o Retorno da Circulação Espontânea (RCE).

Ressalta-se que se o atendimento for realizado de forma rápida e a RCP for bem-sucedida, o paciente tem mais chances de sobrevida. Assim, após a reversão da PCR, a condição clínica do paciente pode se apresentar com boa recuperação. Em contrapartida, na maioria das ocorrências, as vítimas evoluem com disfunções cardiovasculares e, por conseguinte, instabilidade hemodinâmica, o que requer intervenções precoces e assertivas (Rasia, 2016). Destaca-se, ainda, que os pacientes, cujo desfecho seja favorável após a PCR e a RCP, podem evoluir para a Síndrome Pós-Parada Cardíaca (SPPC), caracterizada pela inflamação sistêmica seguida de lesão cerebral, miocárdica, pulmonar e renal. Isso ocorre em razão do estresse oxidativo gerado durante o processo de restabelecimento do fluxo sanguíneo, que sucede o período de isquemia (Lisboa, Borges, \& Monteiro, 2016).

Acentua-se, de forma detalhada, que os aspectos fisiopatológicos da lesão por isquemia e reperfusão, marca registrada da SPPC, apresentam-se por meio de alteração na função e na estrutura tissular, que são perceptíveis após o período de redução 
do fluxo sanguíneo e, posteriormente, de tentativa do restabelecimento da perfusão. Essas alterações resultam em efeitos deletérios às células, em virtude do estresse oxidativo e endoplasmático que são gerados, além de ativarem o processo inflamatório sistêmico (Zhuang, Chen, \& Zhou, 2019).

Dessa forma, torna-se um desafio o tratamento a pacientes que evoluem com a SPPC, ao considerar o risco de deterioração clínica e falência de múltiplos órgãos. Além disso, a incidência da SPPC em pacientes na Unidade de Terapia Intensiva (UTI) está associada à alta taxa de morbimortalidade e o sucesso da reanimação não determina o estado clínico do paciente. A continuidade dos cuidados é indispensável nesse processo em razão das consequências sistêmicas deletérias da parada abrupta da função cardíaca (Pulze, Alves, Paiva, \& Ferretti-Rebustini, 2019).

Nesse cenário, os cuidados pós-PCR realizados pela equipe de enfermagem, substanciais à progressão clínica do paciente, englobam a monitorização hemodinâmica, a realização de exames laboratoriais e cuidados específicos. A equipe deve deter o conhecimento técnico-científico necessário acerca da fisiopatologia da SPPC e das medidas terapêuticas mais adequadas a serem praticadas (Guskuma et al., 2019).

Com efeito, a sobrevivência dos pacientes que sofreram PCR não depende apenas de uma boa assistência na fase aguda, mas também de fatores relacionados ao atendimento pós-ressuscitação. Para Girotra, Nallamothu, Tang e Chan (2020), os dois momentos têm igual relevância na sobrevida do paciente, porém o segundo deve ser adotado como ponto essencial na melhoria da qualidade da atenção à PCR. Analogamente, um bom atendimento após o RCE e o uso de tecnologias apropriadas, asseguram uma melhor qualidade de vida ao paciente através da predição de danos e da assistência adequada (Kocayigit et al., 2021).

Apenas no ano de 2020, a taxa de mortalidade hospitalar de doenças do aparelho circulatório foi de 9,98\%. Dados preliminares do Painel de Monitoramento da Mortalidade CID-10 (SIM-SUS) apontam que, em 2020, a incidência de óbitos com a CID-10 I46 (Parada Cardíaca) foi no montante de 2.120 ocorrências, o que representa um aumento de 51,86\% se comparado ao ano anterior (SIS, 2021). No entanto, o ano de 2020 representou um aumento atípico dos óbitos por essa causa, com o advento da pandemia da COVID-19 no Brasil. Esse aumento, no entanto, tem características atípicas se relacionado aos anos anteriores, pois menos de $24 \%$ dessas mortes se deram em hospitais, isto é, dez pontos percentuais a menos que no ano de 2016 (Sistema de Informação de Saúde [SIS], 2021).

Nesse período, houve mudança no local da ocorrência. Enquanto em 2016 33,98\% desses óbitos ocorreram em hospitais, em 2020 esse percentual foi de apenas 23,58\% (SIS, 2021). Contudo, isso não indica, em si, uma melhora na atenção hospitalar. Numericamente, foram registrados, em ambiente hospitalar, 500 óbitos em 2020 contra 406 em 2019, ao passo que, em domicílio, totalizaram-se 703 em 2019 e 1.308 em 2020. Decerto, a pandemia provocada pelo novo coronavírus, ao fomentar medidas de isolamento social como forma de conter a propagação da doença, pode ter contribuído para essa alteração acentuada.

Frente à alta morbimortalidade associada à SPPC, expressada pelos efeitos nocivos inerentes ao processo fisiopatológico característico, insere-se a atuação da equipe de enfermagem como importante instrumento para subsidiar os cuidados indispensáveis e direcionados aos pacientes que evoluem com esse quadro clínico. Assim, faz-se relevante este estudo, por propiciar o alinhamento de evidências apontadas na literatura voltada para a enfermagem nesse contexto e em virtude da incidência de óbitos relacionados à SPPC. Portanto, diante do cenário supracitado, objetivou-se identificar, através da literatura, a atuação da Enfermagem intensivista frente aos sinais clínicos da SPPC.

\section{Metodologia}

O presente estudo trata-se de uma revisão integrativa da literatura elaborada em conformidade com as seis etapas características desse método e norteada por meio do checklist preconizado pelo PRISMA (Preferred Reporting Items for Systematic Reviews and Meta-Analyses). Essa revisão é definida pela sintetização de estudos levantados na literatura acerca de determinada temática ou questão de pesquisa, com vistas a possibilitar uma visão amplificada e estruturada sobre determinada 
problemática ou tema. Dessarte, propicia o alinhamento de múltiplos estudos, por meio de teorias, ideias e problemas encontrados, relevantes para a compreensão mais integralizada do assunto discutido (SOUSA et al., 2017).

Realizou-se a busca dos artigos por meio da Biblioteca Virtual de Saúde (BVS), na Base de Dados de Enfermagem (BDENF), Literatura Latino Americana e do Caribe em Ciências da Saúde (LILACS) e Medical Literature Review and Online Recovery System (MEDLINE), ambos com acesso on-line. Referente ao tempo utilizado para a busca dos artigos, deu-se entre os meses de fevereiro e agosto de 2021 e utilizaram-se os seguintes descritores: "enfermagem", "Unidade de Terapia Intensiva", "parada Cardíaca", "síndrome pós-parada cardíaca" e "enfermagem centrada no paciente".

Quanto aos cruzamentos dos descritores selecionados, empregaram-se os operadores booleanos. Assim ocorreu no primeiro cruzamento: (enfermagem centrada no paciente) OR (síndrome pós-parada cardíaca) AND (síndrome pós-parada cardíaca). No segundo, os descritores e operadores foram estes: (enfermagem) AND (Unidade de Terapia Intensiva) AND (parada cardíaca). O que resultou em um total de 386 artigos encontrados na primeira busca e 99 na segunda.

Na primeira busca, foram selecionados dez estudos e, na segunda, mais dez, ambos com a aplicação dos critérios de elegibilidade, quais sejam: texto completo; recorte temporal dos últimos 5 anos; idiomas em inglês, português e espanhol; e matérias relevantes ao tema. Foram excluídos os registros duplicados e, por tangenciar o tema, os estudos relacionados ao atendimento pré-hospitalar da parada cardíaca; ao enforcamento; ao uso de óxido nitroso; às cirurgias e às afecções cardíacas; à circulação extracorpórea; à terapia de substituição renal; à anestesia; à estimulação transcraniana; à ressonância magnética; e à associação entre a parada cardíaca e puerpério ou pediatria.

Adicionalmente, dois estudos de repositórios institucionais complementaram a amostra final, sendo um artigo da Universidade Federal da Paraíba (UFPB) e uma tese da Universidade Federal de Santa Catarina (UFSC), alcançando, na totalidade, 22 registros. Diante disso, esta foi a questão norteadora estabelecida: "Qual a atuação da enfermagem na UTI mediante aos sinais clínicos da SPPC?". A Figura 1, a seguir, dispõe do quantitativo inicial e final dos estudos levantados na literatura, por meio do delineamento das etapas executadas durante o processo de busca, seleção e elegibilidade. 
Figura 1: Seleção dos artigos levantados na literatura para composição dos resultados e embasamento teórico, 2021.

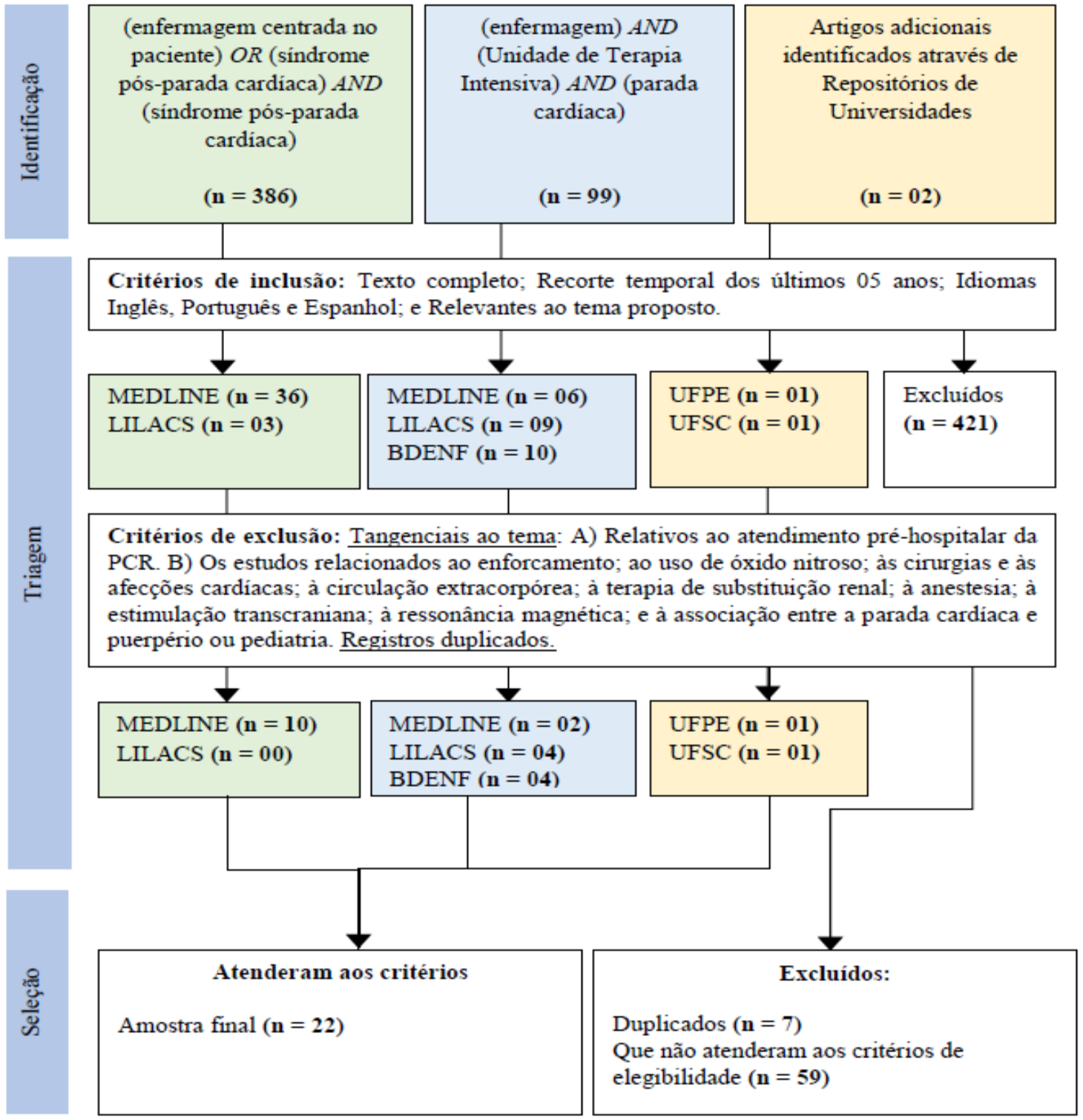

Fonte: Autores com a descrição das etapas executadas para o levantamento dos estudos na literatura (2021).

\section{Resultados e Discussão}

O Quadro 1 discorre sobre a sistematização dos estudos selecionados para a composição da pesquisa, o qual é caracterizado em cinco tópicos em conformidade com as informações necessárias para o desenvolvimento de uma revisão de literatura. Os dados são classificados por título, autores, métodos, base de dados e resultados. 
Quadro 1: Descrição dos estudos identificados na literatura classificados por título, autores, métodos, base de dados e resultados.

\begin{tabular}{|c|c|c|c|c|}
\hline Título & Autores & Métodos & $\begin{array}{c}\text { Base de } \\
\text { dados }\end{array}$ & Resultados \\
\hline $\begin{array}{l}\text { Conhecimento teórico da } \\
\text { enfermagem sobre parada } \\
\text { cardiorrespiratória e } \\
\text { reanimação } \\
\text { cardiocerebral em } \\
\text { Unidade de Terapia } \\
\text { Intensiva }\end{array}$ & $\begin{array}{l}\text { Beccaria, L. M., Santos, K. } \\
\text { F., Trombeta, J. C., } \\
\text { Rodrigues, A. M. S., Barbosa, } \\
\text { T. P. \& Jacon, J. C. }\end{array}$ & $\begin{array}{l}\text { Pesquisa } \\
\text { descritiva com } \\
\text { abordagem } \\
\text { quantitativa }\end{array}$ & $\begin{array}{l}\text { BDENF - } \\
\text { Enfermage } \\
m\end{array}$ & $\begin{array}{l}\text { Parte dos profissionais de enfermagem } \\
\text { participantes da pesquisa estava } \\
\text { desatualizada sobre as diretrizes da PCR, } \\
\text { como também do conhecimento teórico- } \\
\text { prático básico no tocante à RCP, no âmbito } \\
\text { da terapia intensiva. }\end{array}$ \\
\hline $\begin{array}{l}\text { Hipotermia terapêutica: } \\
\text { efeitos adversos, } \\
\text { complicações e cuidados } \\
\text { de enfermagem }\end{array}$ & $\begin{array}{l}\text { Corrêa, L. O., Silveira, R. S., } \\
\text { Mancia, J. R., Corrêa, N. L., } \\
\text { Reinhardt, I. M. S., Lunardi, } \\
\text { V. S., \& Ciconet, R. M. }\end{array}$ & $\begin{array}{l}\text { Pesquisa de } \\
\text { abordagem } \\
\text { quantitativa }\end{array}$ & $\begin{array}{l}\text { LILACS, } \\
\text { BDENF- } \\
\text { Enfermagem }\end{array}$ & $\begin{array}{l}\text { Tremores, bradicardia, hipotensão } \\
\text { queimaduras na pele foram destaques no } \\
\text { contexto dos efeitos adversos. Convergiram } \\
\text { para o trato da pele, o uso do gelo, a sedação } \\
\text { e o conforto. De fato, a hipotermia } \\
\text { terapêutica pôde ser aplicada com } \\
\text { segurança, eficácia e de forma menos } \\
\text { dispendiosa. Contudo, é mister a } \\
\text { qualificação da equipe no esclarecimento de } \\
\text { dúvidas e na contribuição para a adesão e os } \\
\text { cuidados a serem fornecidos. }\end{array}$ \\
\hline $\begin{array}{l}\text { Parada } \\
\text { cardiorrespiratória: } \\
\text { conhecimento dos } \\
\text { profissionais de } \\
\text { enfermagem em uma } \\
\text { unidade de terapia } \\
\text { intensiva }\end{array}$ & $\begin{array}{l}\text { Espindola, M. C. M., } \\
\text { Espindola, M. M. M., Moura, } \\
\text { L. T. R., \& Lacerda, L. C. A. }\end{array}$ & $\begin{array}{l}\text { Estudo } \\
\text { descritivo, } \\
\text { exploratório, de } \\
\text { abordagem } \\
\text { quantitativa }\end{array}$ & $\begin{array}{l}\text { BDENF - } \\
\text { Enfermage } \\
\mathrm{m}\end{array}$ & $\begin{array}{l}\text { Um percentual considerável dos } \\
\text { profissionais de enfermagem que } \\
\text { participaram do estudo não detinha o } \\
\text { conhecimento teórico básico sobre a } \\
\text { assistência aos indivíduos em PCR e sobre a } \\
\text { fisiopatologia característica. Por isso, } \\
\text { reiterou-se a importância da educação } \\
\text { continuada pautada nas diretrizes da AHA. }\end{array}$ \\
\hline $\begin{array}{l}\text { Association of Hospital- } \\
\text { Level Acute } \\
\text { Resuscitation and } \\
\text { Postresuscitation } \\
\text { Survival With Overall } \\
\text { Risk-Standardized } \\
\text { Survival to Discharge } \\
\text { for In-Hospital Cardiac } \\
\text { Arrest }\end{array}$ & $\begin{array}{l}\text { Girotra, S., Nallamothu, B. } \\
\text { K., Tang, Y., \& Chan, P. S. }\end{array}$ & $\begin{array}{l}\text { Estudo de } \\
\text { coorte } \\
\text { observacional }\end{array}$ & MEDLINE & $\begin{array}{l}\text { As descobertas sugerem que os hospitais que } \\
\text { se destacam na sobrevida geral na parada } \\
\text { cardíaca intra-hospitalar, em geral, o fazem } \\
\text { na reanimação aguda ou nos cuidados pós- } \\
\text { terapia, mas não em ambos. Medidas para } \\
\text { fortalecer os cuidados pós-terapia podem } \\
\text { oferecer oportunidades adicionais para } \\
\text { melhorar a sobrevida na parada cardíaca } \\
\text { intra-hospitalar. }\end{array}$ \\
\hline $\begin{array}{l}\text { Conhecimento da equipe } \\
\text { de enfermagem sobre } \\
\text { ressuscitação } \\
\text { cardiopulmonar em um } \\
\text { hospital universitário }\end{array}$ & $\begin{array}{l}\text { Guskuma, E. M., Lopes, M. } \\
\text { C. B. T., Piacezzi, L. H. V., } \\
\text { Okuno, M. F. P., Batista, R. } \\
\text { E. A., \& Campanharo, C. R. } \\
\text { V. }\end{array}$ & $\begin{array}{l}\text { Estudo } \\
\text { transversal, } \\
\text { descritivo e } \\
\text { quantitativo }\end{array}$ & $\begin{array}{l}\text { LILACS, } \\
\text { BDENF- } \\
\text { Enfermagem }\end{array}$ & $\begin{array}{l}\text { Houve uma relação entre elevadas taxas de } \\
\text { conhecimento sobre a PCR, maior nível de } \\
\text { educação, renda superior a três salários } \\
\text { mínimos, especialização em áreas críticas, } \\
\text { tempo de experiência inferior a cinco anos e } \\
\text { treinamento em suporte avançado de vida } \\
\text { completado a tempo inferior a cinco anos. } \\
\text { Coletivamente, a maior frequência de } \\
\text { respostas corretas foram associadas à RCP e } \\
\text { a menor frequência aos conhecimentos em } \\
\text { áreas não críticas. }\end{array}$ \\
\hline
\end{tabular}




\begin{tabular}{|c|c|c|c|c|}
\hline $\begin{array}{l}\text { Prognostic value of } 18 F- \\
\text { FDG brain PET as an } \\
\text { early indicator of } \\
\text { neurological outcomes in } \\
\text { a rat model of post- } \\
\text { cardiac arrest syndrome }\end{array}$ & $\begin{array}{l}\text { Kim, D., Yoon, HJ., \& Lee, } \\
\text { W.J. }\end{array}$ & $\begin{array}{l}\text { Estudo } \\
\text { experimental }\end{array}$ & MEDLINE & $\begin{array}{l}\text { Sugerem a utilidade potencial de } F D G P E T \\
\text { scan na predição precoce de resultados } \\
\text { neurológicos em pacientes com SPPC } \\
\text { através da medição do metabolismo } \\
\text { glicolítico. }\end{array}$ \\
\hline $\begin{array}{l}\text { Relationship between the } \\
\text { legal nurse staffing } \\
\text { standard and patient } \\
\text { survival after } \\
\text { perioperative cardiac } \\
\text { arrest: } \text { A cross-sectional } \\
\text { analysis of Korean } \\
\text { administrative data }\end{array}$ & Kim, Y., Kim, J., \& Shin, S. A. & $\begin{array}{l}\text { Avaliação } \\
\text { econômica em } \\
\text { saúde }\end{array}$ & MEDLINE & $\begin{array}{l}\text { A taxa de sobrevida dos pacientes após PCR } \\
\text { está relacionada ao dimensionamento } \\
\text { pertinente de pessoal. Estabelecer, pois, um } \\
\text { quantitativo de profissionais adequado é } \\
\text { necessário. }\end{array}$ \\
\hline $\begin{array}{l}\text { Neurological Outcomes of } \\
\text { Normothermia versus } \\
\text { Targeted Temperature } \\
\text { Management in Post- } \\
\text { cardiac Arrest Syndrome }\end{array}$ & $\begin{array}{l}\text { Kocayigit, H., Suner, K. O., } \\
\text { Kaya, B., Tomak, Y., Tuna, } \\
\text { A. T., \& Erdem, A. F. }\end{array}$ & $\begin{array}{l}\text { Estudo de } \\
\text { coorte } \\
\text { retrospectivo }\end{array}$ & MEDLINE & $\begin{array}{l}\text { A avaliação dos resultados neurológicos foi } \\
\text { melhor em pacientes pós-parada cardíaca } \\
\text { com RCE, submetidos à terapia de } \\
\text { Gerenciamento de } \\
\text { Direcionada. No entanto, não houve } \\
\text { diferença significativa na mortalidade entre } \\
\text { os grupos de intervenção e de controle. }\end{array}$ \\
\hline $\begin{array}{l}\text { Avaliação do } \\
\text { conhecimento dos } \\
\text { enfermeiros sobre os } \\
\text { cuidados pós-parada } \\
\text { cardiorrespiratória }\end{array}$ & $\begin{array}{l}\text { Lisboa, N. L., Borges, M. S., } \\
\text { \& Monteiro, P. S. }\end{array}$ & $\begin{array}{l}\text { Estudo } \\
\text { descritivo, de } \\
\text { abordagem } \\
\text { quantitativa }\end{array}$ & $\begin{array}{l}\text { Repositório } \\
\text { da UFPE }\end{array}$ & $\begin{array}{l}\text { A média da nota obtida pelos respondentes } \\
\text { foi insatisfatória, além de identificadas } \\
\text { lacunas no conhecimento acerca de cuidados } \\
\text { pós-PCR. O grupo de enfermeiros que } \\
\text { obteve melhor desempenho participou de } \\
\text { mais cursos de atualização no último ano. }\end{array}$ \\
\hline $\begin{array}{l}\text { The post-cardiac arrest } \\
\text { syndrome: A case for } \\
\text { lung-brain coupling and } \\
\text { opportunities for } \\
\text { neuroprotection }\end{array}$ & $\begin{array}{l}\text { Mai, N., Miller,Rhodes, K., } \\
\text { Knowlden, S., \& Halterman, } \\
\text { M. W. }\end{array}$ & $\begin{array}{l}\text { Artigo de } \\
\text { revisão }\end{array}$ & MEDLINE & $\begin{array}{l}\text { Evidências recentes implicaram no pulmão } \\
\text { como moderador da inflamação sistêmica } \\
\text { após uma lesão somática remota. As } \\
\text { intervenções sobre o gatilho imune- } \\
\text { dependente do pulmão podem resultar na } \\
\text { melhoria dos resultados do paciente após a } \\
\text { parada cardíaca e possivelmente outras } \\
\text { lesões neurológicas agudas. }\end{array}$ \\
\hline $\begin{array}{l}\text { Oxygen Exposure During } \\
\text { Cardiopulmonary } \\
\text { Resuscitation Is } \\
\text { Associated With Cerebral } \\
\text { Oxidative Injury in a } \\
\text { Randomized, Blinded, } \\
\text { Controlled, Preclinical } \\
\text { Trial }\end{array}$ & $\begin{array}{l}\text { Marquez, A. M., Morgan, R. } \\
\text { W., Ko, T., Landis, W. P., } \\
\text { Hefti, M. M., Mavroudis, C. } \\
\text { D., McManus, M. J., } \\
\text { Karlsson, M., Starr, J., } \\
\text { Roberts, A. L., Lin, Y., } \\
\text { Nadkarni, V., Licht, D. J., } \\
\text { Berg, R. A., Sutton, R. M., \& } \\
\text { Kilbaugh, T. J. }\end{array}$ & $\begin{array}{l}\text { Ensaio clínico } \\
\text { prospectivo e } \\
\text { randomizado }\end{array}$ & MEDLINE & $\begin{array}{l}\text { Houve lesão ao tecido cerebral posterior ao } \\
\text { RCE devido à aplicação de oxigenação de } \\
1,0 \text { inspirado durante a RCP. }\end{array}$ \\
\hline $\begin{array}{l}\text { Results of the } \\
\text { implementation of } \\
\text { integrated care after } \\
\text { cardiorespiratory arrest } \\
\text { in a university hospital }\end{array}$ & $\begin{array}{l}\text { Mauricio, E. C. B., Lopes, M. } \\
\text { C. B. T., Batista, R. E. A., } \\
\text { Okuno, M. F. P., \& } \\
\text { Campanharo, C. R. V. }\end{array}$ & $\begin{array}{l}\text { Estudo } \\
\text { retrospectivo, } \\
\text { analítico e } \\
\text { quantitativo }\end{array}$ & $\begin{array}{l}\text { LILACS, } \\
\text { BDENF- } \\
\text { Enfermagem }\end{array}$ & $\begin{array}{l}\text { Dentre as intervenções aos pacientes em pós- } \\
\text { PCR, a obtenção de via aérea avançada e a } \\
\text { sondagem vesical de demora consistiram nos } \\
\text { procedimentos mais frequentemente } \\
\text { realizados. O risco de óbito foi minimizado } \\
\text { em razão do controle dos sinais vitais e da } \\
\text { transferência para a UTI. Os pacientes cujo } \\
\text { quadro dispensava o uso de drogas } \\
\text { vasoativas, com identificação precoce da } \\
\text { causa, obtiveram melhores resultados } \\
\text { neurológicos. }\end{array}$ \\
\hline $\begin{array}{l}\text { Better Nurse Staffing } \\
\text { and Nurse Work } \\
\text { Environments } \\
\text { Associated With } \\
\text { Increased Survival of }\end{array}$ & $\begin{array}{l}\text { McHugh, M. D., Rochman, } \\
\text { M. F., Sloane, D. M., Berg, R. } \\
\text { A., Mancini, M. E., Nadkarni, } \\
\text { V. M., Merchant, R. M., \& } \\
\text { Aiken, L. H. }\end{array}$ & $\begin{array}{l}\text { Estudo } \\
\text { Transversal }\end{array}$ & MEDLINE & $\begin{array}{l}\text { À proporção que o ambiente de trabalho seja } \\
\text { harmonioso, a carga horária e a quantidade } \\
\text { de pacientes sejam adequadas ao } \\
\text { profissional enfermeiro, haverá reduzido }\end{array}$ \\
\hline
\end{tabular}




\begin{tabular}{|c|c|c|c|c|}
\hline $\begin{array}{l}\text { In-Hospital Cardiac } \\
\text { Arrest Patients }\end{array}$ & & & & $\begin{array}{l}\text { risco de mortalidade dos pacientes que } \\
\text { apresentam PCR em ambiente hospitalar. }\end{array}$ \\
\hline $\begin{array}{l}\text { Elimination of glutamate } \\
\text { using CRRT for } 72 \mathrm{~h} \text { in } \\
\text { patients with post- } \\
\text { cardiac arrest syndrome: } \\
\text { A randomized clinical } \\
\text { pilot trial }\end{array}$ & $\begin{array}{l}\text { Nee, J., Jörres, A., Krannich, } \\
\text { A., Leithner, C., Schroeder, } \\
\text { T., Munk, A. L., Enghard, P., } \\
\text { Moore, C., Steppan, S., \& } \\
\text { Storm, C. }\end{array}$ & $\begin{array}{l}\text { Ensaio clínico } \\
\text { prospectivo e } \\
\text { randomizado }\end{array}$ & MEDLINE & $\begin{array}{l}\text { Análise e descarte da hipótese da terapia de } \\
\text { Hemodiafiltração Venosa Contínua como } \\
\text { tratamento pós-parada cardíaca para } \\
\text { proteção neurológica por redução de níveis } \\
\text { dos mediadores de morte de células do } \\
\text { tecido cerebral (glutamato e glutamina). } \\
\text { Pacientes em pós-parada cardíaca que } \\
\text { compuseram o ensaio não apresentaram } \\
\text { alterações séricas desses marcadores. }\end{array}$ \\
\hline $\begin{array}{l}\text { External validation of a } \\
\text { risk classification at the } \\
\text { emergency department of } \\
\text { post-cardiac arrest } \\
\text { syndrome patients } \\
\text { undergoing targeted } \\
\text { temperature management }\end{array}$ & $\begin{array}{l}\text { Nishikimi, M., Ogura, T., } \\
\text { Nishida, K., Takahashi, K., } \\
\text { Nakamura, M., Matsui, S., } \\
\text { Matsuda, N., \& Iwami, T. }\end{array}$ & $\begin{array}{l}\text { Registro } \\
\text { multicêntrico e } \\
\text { prospectivo }\end{array}$ & MEDLINE & $\begin{array}{l}\text { A validação de uma versão mais simples de } \\
\text { um protocolo resultou em melhoria na } \\
\text { previsão das consequências neurológicas } \\
\text { decorridas da SPPC, em pacientes } \\
\text { acometidos fora do ambiente hospitalar e } \\
\text { tratados com uma temperatura entre } 33-36^{\circ} \\
\text { C. }\end{array}$ \\
\hline $\begin{array}{l}\text { Cardiopulmonary arrest } \\
\text { is the most frequent cause } \\
\text { of the unresponsive } \\
\text { wakefulness syndrome: A } \\
\text { prospective population- } \\
\text { based cohort study in } \\
\text { Austria }\end{array}$ & Pichler, G., \& Fazekas, F. & $\begin{array}{l}\text { Estudo de } \\
\text { coorte } \\
\text { prospectivo }\end{array}$ & MEDLINE & $\begin{array}{l}\text { Aponta novos dados sobre o agente causador } \\
\text { da síndrome da vigília em resposta, à medida } \\
\text { que está associada à hipóxia tecidual } \\
\text { encefálica pós-parada cardíaca, com uma } \\
\text { incidência prevalente no gênero masculino. }\end{array}$ \\
\hline $\begin{array}{l}\text { Incidência e fatores } \\
\text { associados à parada } \\
\text { cardiorrespiratória nas } \\
\text { primeiras } 24 \text { horas de } \\
\text { internação em Unidades } \\
\text { de Terapia Intensiva }\end{array}$ & $\begin{array}{l}\text { Pulze, G., Alves, W. S., \& } \\
\text { Paiva, B. C., \& Ferretti- } \\
\text { Rebustini, R. E. L. }\end{array}$ & $\begin{array}{l}\text { Estudo } \\
\text { secundário }\end{array}$ & LILACS & $\begin{array}{l}\text { A gravidade admissional é um fator preditor } \\
\text { para a ocorrência da PCR. Ainda, a baixa } \\
\text { perfusão tecidual e o rebaixamento do nível } \\
\text { de consciência estão relacionados à PCR. }\end{array}$ \\
\hline $\begin{array}{l}\text { Cuidados de enfermagem } \\
\text { a pacientes em pós- } \\
\text { parada cardiorrespiratória } \\
\text { internados em Unidade } \\
\text { de Terapia Intensiva: } \\
\text { construção e validação de } \\
\text { protocolo }\end{array}$ & Rasia, M. A. & Tese & $\begin{array}{l}\text { Repositório } \\
\text { da UFSC }\end{array}$ & $\begin{array}{l}\text { A elaboração e a validação de protocolos são } \\
\text { instrumentos eficazes na promoção do } \\
\text { cuidado de enfermagem em pacientes pós- } \\
\text { PCR. Essas estratégias proporcionam maior } \\
\text { adesão a esses cuidados, além da } \\
\text { compreensão do profissional acerca da } \\
\text { importância da assistência nesse período. }\end{array}$ \\
\hline $\begin{array}{l}\text { Parada cardiorrespiratória } \\
\text { e educação continuada } \\
\text { em Unidade de Terapia } \\
\text { Intensiva }\end{array}$ & $\begin{array}{l}\text { Silva, R., Rodrigues, J. \& } \\
\text { Nunes, N. }\end{array}$ & $\begin{array}{l}\text { Estudo } \\
\text { transversal, } \\
\text { com abordagem } \\
\text { exploratória e } \\
\text { descritiva }\end{array}$ & LILACS & $\begin{array}{l}\text { É imperiosa a necessidade de a enfermagem } \\
\text { estar em atualizações constantes acerca do } \\
\text { adequado manejo clínico da PCR e daquilo } \\
\text { que a sucede. }\end{array}$ \\
\hline $\begin{array}{l}\text { Proportion of time spent } \\
\text { in blood glucose range } \\
70 \text { to } 140 \mathrm{mg} / \mathrm{dL} \text { is } \\
\text { associated with increased } \\
\text { survival in patients } \\
\text { admitted to ICU after } \\
\text { cardiac arrest }\end{array}$ & $\begin{array}{l}\text { Zhou, D., Li, Z., Shi, G., \& } \\
\text { Zhou, J. }\end{array}$ & $\begin{array}{l}\text { Análise } \\
\text { retrospectiva } \\
\text { multicêntrica }\end{array}$ & MEDLINE & $\begin{array}{l}\text { O valor da glicose está associado a um bom } \\
\text { prognóstico do paciente pós-PCR. Níveis } \\
\text { que variam entre } 70 \text { e } 140 \mathrm{mg} / \mathrm{dL} \text { estão } \\
\text { relacionados a uma taxa de sobrevivência } \\
\text { acentuada, enquanto quadros de } \\
\text { hiperglicemia se aparelham, } \\
\text { predominantemente, ao número de óbitos. }\end{array}$ \\
\hline $\begin{array}{l}\text { High plasma levels of } \\
\text { pro-inflammatory factors } \\
\text { interleukin-17 and } \\
\text { interleukin- } 23 \text { are } \\
\text { associated with poor } \\
\text { outcome of cardiac- } \\
\text { arrest patients: a single } \\
\text { center experience }\end{array}$ & $\begin{array}{l}\text { Zhuang, YG., Chen, YZ., } \\
\text { Zhou, SQ., Peng, Hu., Chen, } \\
\text { YQ., \& Li, DJ. }\end{array}$ & $\begin{array}{l}\text { Estudo clínico } \\
\text { observacional } \\
\text { prospectivo }\end{array}$ & MEDLINE & $\begin{array}{l}\text { Níveis plasmáticos elevados de creatinina, } \\
\text { de enzimas hepáticas e de interleucina } 17 \text { e } \\
23 \text {, em pacientes pós-PCR, estão associados } \\
\text { a um número de óbitos mais alto. }\end{array}$ \\
\hline
\end{tabular}


Fonte: Autores com resultado da pesquisa (2021).

A partir da definição e do conhecimento do que seja PCR, de sua incidência, dos locais de ocorrência e dos efeitos fisiopatológicos desencadeados por esse evento, a equipe de enfermagem desempenha atribuições fundamentais desde a sua prevenção, com a identificação dos sinais clínicos antecessores (Espíndola, Espindola, Moura e Lacerda, 2017), até o período de pós ressuscitação cardiopulmonar. Sabe-se, ainda, que a dimensão do comprometimento neurológico depende do grau de hipoxemia ao qual o tecido cerebral é exposto, podendo ocorrer lesão irreversível após 5 a 10 minutos da inteira interrupção do fluxo sanguíneo (Rasia, 2016).

Nesse viés, frisa-se que os pacientes admitidos na Unidade de Terapia Intensiva (UTI) com quadros de elevada criticidade devem ter uma atenção especial, pois a gravidade admissional é fator de risco para a PCR. Desse modo, isso é evidenciado em um estudo secundário realizado em nove UTIs, em que se concluiu que a porcentagem do número de ocorrência desse evento consistiu em 3,6\% do total de prontuários avaliados no primeiro dia de internação (Pulze et al., 2019). A Tabela 1 apresenta os dados do referido estudo, caracterizado pela média da pontuação resultante da aplicação da Escala de Coma de Glasgow (ECG) e da gravidade do quadro clínico geral, os quais foram relacionados aos fatores preditivos da PCR.

Tabela 1: Média da pontuação dos fatores associados à predisposição à PCR no momento de admissão na UTI em comparação à pontuação, conforme a ocorrência do agravamento (2019), 2021.

\section{Momento de admissão na Unidade de Terapia Intensiva (UTI)}

Momento de ocorrência da Parada Cardiorrespiratória (PCR)

\begin{tabular}{ccccc}
\hline Fatores & Média da pontuação & Desvio Padrão & Média da pontuação & Desvio Padrão \\
\hline $\begin{array}{c}\text { Nível de consciência } \\
\text { (ECG) }\end{array}$ & 11,70 & 4,6 & 6,55 & 4,435 \\
\hline $\begin{array}{c}\text { Gravidade do quadro } \\
\text { clínico }\end{array}$ & 30,22 & 15,02 & 37,47 & 18,041 \\
\hline
\end{tabular}

Fonte: Autores com dados de Pulze et al (2019), (2021).

Com a premissa de que a identificação de um quadro agudo de PCR e a sua intervenção imediata são fatores determinantes no prognóstico do paciente, a enfermagem atua diretamente no cuidado ao paciente crítico. Esse cuidado se dá a partir da monitorização hemodinâmica, da otimização da atividade e do desempenho cardiopulmonar, da termorregulação, da supervisão dos parâmetros ventilatórios e do desenvolvimento do raciocínio clínico (Rasia, 2016).

Dessarte, no que concerne aos cuidados de enfermagem pós-PCR, a sobrevida dos pacientes está intimamente relacionada à manutenção do sistema cardiorrespiratório, durante o restabelecimento dos padrões vitais nas primeiras 24 horas e o RCE. Esse processo de sustentação é estabelecido por meio da oxigenoterapia, em que se objetiva atingir e estabilizar a saturação de oxigênio entre $94 \%$ e $96 \%$ e, concomitantemente, controlar a temperatura e a pressão arterial (Maurício, Lopes, Batista, Okuno, \& Campanharo, 2018).

Referente a esse período pós-PCR, Pichler e Fazekas (2016) evidenciam, em seu estudo, que a síndrome da vigília sem resposta, conhecida anteriormente como "estado vegetativo", é ocasionada por traumas cerebrais e, paralelamente, permite que o paciente apenas apresente a movimentação dos olhos, sem expor nenhuma outra reação corporal e comportamental. Estudos anteriores apontavam que a maior causa dessa síndrome consistia no traumatismo cranioencefálico. Em contraposição, para o referido autor, o agente causador da síndrome da vigília sem resposta decorre da PCR associada à hipóxia tecidual encefálica, tendo uma maior incidência no gênero masculino. 
Acrescenta-se que, no cerne deste estudo, a SPPC, secundária à RCE, se apresenta como um desafio aos profissionais de enfermagem devido às repercussões clínicas ao paciente. Essas alterações fisiopatológicas demandam cuidados imediatos por causa da morbidade e da mortalidade associadas. Dessa forma, as intervenções objetivam a estabilização do quadro, por intermédio da monitorização hemodinâmica; prevenção à hipertermia; sondagem vesical de demora, para o controle do débito urinário e balanço hídrico; eletrocardiograma de 12 derivações; radiografia de tórax e manutenção da sedação (Maurício et al., 2018). Pacientes com esse desfecho clínico demandam cuidados intensivos, logo, devem ser transferidos precocemente para a UTI, ocasião em que a assistência é efetuada em um nível de complexidade cabível. Além disso, para Maurício et al. (2018), quando o uso de drogas vasoativas forem imprescindíveis, os indivíduos terão menos chances de sobrevida.

Nesse sentido, exames laboratoriais complementares são fundamentais na SPPC, na medida em que a partir da identificação de citocinas inflamatórias e enzimas alteradas, toda a equipe será direcionada a realizar o adequado manejo clínico ao paciente, ao traçar medidas de prevenção, tratamento e cuidado. Então, tão logo seja percebida alterações metabólicas por meio de mudanças nos parâmetros de normalidade e em virtude da intervenção diante dos achados, o paciente terá melhor prognóstico (Zhuang et al., 2020).

Ainda, exames glicêmicos auxiliam na prevenção de dano ao tecido cerebral, já que estudos apontam que quadros de hiperglicemia, isto é, o aumento da concentração de glicose sanguínea, é fator que predispõe dano neurológico. Dessa forma, é mister intervir na avaliação frequente da glicemia, a fim de certificar-se se os parâmetros estão dentro da faixa esperada, ou seja, entre 70 a $100 \mathrm{mg} / \mathrm{dL}$, valor relacionado à redução da mortalidade em pacientes críticos (Zhou, Li, Shi, \& Zhou, 2020).

Salienta-se que, a partir da interpretação do eletrocardiograma (ECG), é possível reconhecer síndromes coronarianas agudas (SCA) e, com esse reconhecimento, intervir na patologia inicial, de modo a atenuar o risco de uma nova PCR e posterior SPPC. Além disso, a realização de radiografia de tórax, conforme a clínica do paciente, faz-se necessária, porque a causa da PCR pode estar associada a um quadro de pneumotórax. Então, uma vez prescrito esse exame, é possível realizar a identificação (Rasia, 2016).

O uso da terapia de refrigeramento é uma alternativa para diminuir as sequelas em pacientes na SPPC. Essa técnica torna-se neuroprotetora ao ativar os mecanismos anti-apoptóticos e, por conseguinte, aumentar a liberação da proteína p53, responsável por contribuir com a reparação celular após a isquemia local. Dessa maneira, o procedimento reduz a pressão intracraniana ao retardar o traspassamento vascular e, assim, minimizar o edema cerebral. A terapia de resfriamento possui um grande custo benefício além de apresentar uma melhora significativa dos pacientes submetidos (Corrêa et al., 2018).

Em relação à atuação da equipe de enfermagem nos cuidados ao paciente durante o resfriamento, objetiva-se minimizar os efeitos adversos ocasionados pela técnica, por intermédio de ações preventivas às queimaduras, decorrentes do gelo, bem como outras intervenções devem ser implementadas, tais como a passagem de sonda nasogástrica e vesical, com o pressuposto de que o paciente se encontra sedado e apresenta condições fisiológicas reduzidas em virtude da hipotermia induzida (Corrêa et al., 2018).

Outrossim, destaca-se a importância da implantação de termômetro esofágico para a monitorização da temperatura interna dos órgãos, com vistas a maior segurança do paciente durante a terapia de refrigeração, bem como a instalação e verificação da pressão arterial média. Nesse viés, a aplicação de procedimentos para monitorização dos sinais vitais do paciente é indispensável, para prevenir os efeitos adversos que esse procedimento é capaz de ocasionar (Corrêa et al., 2018).

Com efeito, sabe-se que ambientes de trabalho harmoniosos e detentores de insumos e equipamentos primordiais à assistência à saúde estão associados à melhoria da prognose de pacientes em pós-PCR. Ademais, a proporção de profissionais de enfermagem para cada paciente e a sua carga horária de trabalho influenciam diretamente os resultados do tratamento, pois locais com boas condições de exercer o cuidado assistencial no trato da saúde e com número de pessoal adequado proporcionam maior qualidade no tratamento fornecido (McHugh et al., 2016). 
Portanto, o dimensionamento da equipe de enfermagem durante a prevenção à PCR e, posterior assistência no período da SPPC, influencia no bom desenvolvimento futuro do paciente. Percebe-se que a taxa de sobrevida após PCR é alta em hospitais onde a equipe de enfermagem é composta por um número correto de profissionais. Por outro lado, em instituições que apresentam deficiência nesse número, o índice de óbitos é relativamente proeminente. Em síntese, obedecer criteriosamente o dimensionamento de pessoal é indubitável. (Kim, Kim, \& Shin, 2019).

Ainda, é substancial que a enfermagem esteja em constante capacitação frente às intervenções ao paciente clinicamente grave, pois a atuação profissional, no âmbito da saúde, exige atualização mediante leituras, cursos e capacitações. O enfermeiro, como líder da equipe, deve implementar a educação continuada no setor, para que a equipe esteja a postos na identificação de sinais de uma PCR à beira do leito e consequente SPPC, em que a imediata assistência possibilitaria reduzir o risco de morte nesses pacientes gravemente enfermos (Silva, Rodrigues, \& Nunes, 2017).

Assim, nota-se, que a oxigenoterapia aplicada de forma exacerbada durante a RCP pode desencadear efeitos reversos às vítimas, em virtude da hiperóxia, causadora de lesões oxidativas ao tecido cerebral. Em conjunto com os danos decorridos do RCE, essa problemática intensifica os efeitos deletérios que sucedem a SPPC ao sistema nervoso. Diante disso, reitera-se o importante papel da equipe de enfermagem em estar em constante atualização dos conhecimentos, para reduzir os riscos relacionados às intervenções aplicadas erroneamente a esses pacientes (Marquez et al., 2020).

Ademais, a falta de uma classificação de risco e/ou manejo clínico específica para os pacientes em SPPC é um entrave durante o tratamento desse quadro. Desse modo, a validação de um protocolo acarretaria em um melhor direcionamento à equipe de enfermagem, como também facilitaria esse processo. Frente a isso, Nishikimi et al. (2019) buscaram, em sua respectiva pesquisa, validar uma classificação de risco com uma versão mais simples e acessível, baseada no escore de hipotermia terapêutica pós-parada cardíaca, que eles desenvolveram. Portanto, concluiu-se que a classificação propiciou presumir os resultados neurológicos com alto rigor em indivíduos em SPPC.

\section{Conclusão}

Nestas circunstâncias, pôde-se perceber que o sucesso do tratamento mediante aos sinais clínicos da SPPC dependerá fortemente da interação e cooperação entre a equipe de enfermagem e deve ser baseado na combinação de múltiplos fatores que determinarão o bom prognóstico do paciente. Ao considerar a suscetibilidade às complicações e ao elevado risco de mortalidade que esses indivíduos apresentam, esses profissionais desempenham atribuições essenciais. Mormente, como incumbência primária, requer o conhecimento dos aspectos clínicos e fisiopatológicos e das implicações da SPPC.

Nota-se que a importância da identificação precoce dos sinais clínicos desse agravamento, à beira do leito, reflete na atuação chave que a enfermagem desempenha, em função de estar em contato direto com esses pacientes no ambiente de terapia intensiva. Dessa maneira, em face da alta complexidade que o setor dispõe, e especialmente a gravidade desses pacientes, os profissionais devem ser periodicamente capacitados. Para tanto, o ambiente não deve somente dispor de educação continuada, como também deve fornecer boas condições de trabalho e carga horária pertinente, haja vista a importância desses detalhes e a sua influência na qualidade da assistência concedida. De forma que fica evidente que um bom atendimento se baseia na tríade previsibilidade-assistência-equipe.

À vista disso, entre os obstáculos encontrados durante o desenvolvimento deste estudo e como possível contribuição para posteriores estudos, acentua-se a escassez de pesquisas voltadas para a enfermagem no cenário em análise, como também, a necessidade de elaboração de um protocolo clínico padrão de reconhecimento e manejo adequado da SPPC. Esse protocolo deve ser baseado em evidências e validado cientificamente, de modo que seria possível direcionar as intervenções, com o intuito de alcançar a viabilização da prática clínica da equipe, por meio do efetivo gerenciamento do cuidado. 


\section{Referências}

AHA. (2020). Destaques das Diretrizes da American Heart Association 2020 para RCP e ACE. American Heart Association (AHA). Dallas: AHA. https://cpr.heart.org/-/media/cpr-files/cpr-guidelines-files/highlights/hghlghts_2020eccguidelines_portuguese.pdf.

Beccaria, L. M., Santos, K. F., Trombeta, J. C., Rodrigues, A. M. S., Barbosa, T. P. \& Jacon, J. C. (2017). Conhecimento teórico da enfermagem sobre parada cardiorrespiratória e reanimação cardiocerebral em unidade de terapia intensiva. CuidArte, Enferm 11(1): 51-58. https://pesquisa.bvsalud.org/portal/resource/pt/biblio-1027730.

Corrêa, L. O., Silveira, R. S., Mancia, J. R., Corrêa, N. L., Reinhardt, I. M. S., Lunardi, V. S., \& Ciconet, R. M. (2018). Hipotermia terapêutica: efeitos adversos, complicações e cuidados de enfermagem. Enfermagem em Foco, 9(4). https://pesquisa.bvsalud.org/portal/resource/pt/biblio-1028389.

Espindola, M. C. M., Espindola, M. M. M., Moura, L. T. R., \& Lacerda, L. C. A. (2017). Parada cardiorrespiratória: conhecimento dos profissionais de enfermagem em uma unidade de terapia intensiva. Revista de Enfermagem UFPE on-line, 11(7), 2773-2778. https://periodicos.ufpe.br/revistas/revistaenfermagem/article/view/23452/19162.

Ferreira, F. S., Garrido, L. M. M., Oliveira, R. C., Moraes, M. A., Pires, C. G. S., \& Mussi, F. C. (2018). Uso do metrônomo na ressuscitação cardiopulmonar em uma Unidade de Terapia Intensiva. Revista Baiana de Enfermagem, 32, e27912. http://www.revenf.bvs.br/scielo.php?script=sci_arttext\&pid=S217886502018000100602 .

Girotra, S., Nallamothu, B. K., Tang, Y., \& Chan, P. S. (2020). Para a American Heart Association Get With The Guidelines - Resuscitation Investigators. Associação de Reanimação Aguda em Nível Hospitalar e Sobrevivência Pós-Ressuscitação com Sobrevivência Padronizada de Risco Geral para Alta para Parada Cardíaca Hospitalar. JAMA Netw Open. 3 (7): e2010403. https://pesquisa.bvsalud.org/portal/resource/pt/mdl-32648925.

Guskuma, E. M., Lopes, M. C. B. T., Piacezzi, L. H. V., Okuno, M. F. P., Batista, R. E. A., \& Campanharo, C. R. V. (2019). Conhecimento da equipe de enfermagem sobre ressuscitação cardiopulmonar em um hospital universitário. Revista Eletrônica De Enfermagem, 21. https://pesquisa.bvsalud.org/portal/resource/pt/biblio-1119020.

Kim, D., Yoon, HJ., \& Lee, W.J. (2019). Prognostic value of 18F-FDG brain PET as an early indicator of neurological outcomes in a rat model of post-cardiac arrest syndrome. Sci Rep 9, 14798. https://pesquisa.bvsalud.org/portal/resource/pt/mdl-31616019.

Kim, Y., Kim, J., \& Shin, S. A. (2019). Relationship between the legal nurse staffing standard and patient survival after perioperative cardiac arrest: A crosssectional analysis of Korean administrative data, International Journal of Nursing Studies, Volume 89, Pages 104-111, ISSN 0020-7489. https://pesquisa.bvsalud.org/portal/resource/pt/mdl-30359876.

Kocayigit, H., Suner, K. O., Kaya, B., Tomak, Y., Tuna, A. T., \& Erdem, A. F. (2021). Neurological Outcomes of Normothermia versus Targeted Temperature Management in Post-cardiac Arrest Syndrome. Journal of the College of Physicians and Surgeons--Pakistan : JCPSP, 30(5), 497-501. https://pesquisa.bvsalud.org/portal/resource/pt/mdl-34027857.

Lisboa, N. L., Borges, M. S., \& Monteiro, P. S. (2016). Avaliação do conhecimento dos enfermeiros sobre os cuidados pós-parada cardiorrespiratória. Revista de Enfermagem UFPE on-line, [S.1.], v. 10, n. 10, p. 3778-3786, ISSN 1981-8963. https://periodicos.ufpe.br/revistas/revistaenfermagem/article/view/11443.

Mai, N., Miller-Rhodes, K., Knowlden, S., \& Halterman, M. W. (2019). The post-cardiac arrest syndrome: A case for lung-brain coupling and opportunities for neuroprotection. Journal of Cerebral Blood Flow \& Metabolism. 39(6):939-958. https://pesquisa.bvsalud.org/portal/resource/pt/mdl-30866740.

Marquez, A. M., Morgan, R. W., Ko, T., Landis, W. P., Hefti, M. M., Mavroudis, C. D., McManus, M. J., Karlsson, M., Starr, J., Roberts, A. L., Lin, Y., Nadkarni, V., Licht, D. J., Berg, R. A., Sutton, R. M., \& Kilbaugh, T. J. (2020). Oxygen Exposure During Cardiopulmonary Resuscitation Is Associated With Cerebral Oxidative Injury in a Randomized, Blinded, Controlled, Preclinical Trial. Journal of the American Heart Association, 9(9), e015032. https://pesquisa.bvsalud.org/portal/resource/pt/mdl-32321350.

Mauricio, E. C. B., Lopes, M. C. B. T., Batista, R. E. A., Okuno, M. F. P., \& Campanharo, C. R. V. (2018). Results of the implementation of integrated care after cardiorespiratory arrest in a university hospital. Revista Latino-Americana de Enfermagem, $26, \quad$ e2993. https://pesquisa.bvsalud.org/portal/resource/pt/biblio-961197.

McHugh, M. D., Rochman, M. F., Sloane, D. M., Berg, R. A., Mancini, M. E., Nadkarni, V. M., Merchant, R. M., \& Aiken, L. H. (2016). American Heart Association's Get With The Guidelines-Resuscitation Investigators Better Nurse Staffing and Nurse Work Environments Associated With Increased Survival of In-Hospital Cardiac Arrest Patients, Medical Care: Volume 54 - Issue 1 - p 74-80. https://pesquisa.bvsalud.org/portal/resource/pt/mdl-26783858.

Nee, J., Jörres, A., Krannich, A., Leithner, C., Schroeder, T., Munk, A. L., Enghard, P., Moore, C., Steppan, S., \& Storm, C. (2019). Elimination of glutamate using CRRT for $72 \mathrm{~h}$ in patients with post-cardiac arrest syndrome: A randomized clinical pilot trial. Resuscitation, 144, 54-59. https://doi.org/10.1016/j.resuscitation.2019.09.020.

Nishikimi, M., Ogura, T., Nishida, K., Takahashi, K., Nakamura, M., Matsui, S., Matsuda, N., \& Iwami, T. (2019). External validation of a risk classification at the emergency department of post-cardiac arrest syndrome patients undergoing targeted temperature management, Resuscitation, Volume 140, Pages 135-141, ISSN 0300-9572. https://pesquisa.bvsalud.org/portal/resource/pt/mdl-31153943.

Pichler, G., \& Fazekas, F. (2016). Cardiopulmonary arrest is the most frequent cause of the unresponsive wakefulness syndrome: A prospective populationbased cohort study in Austria, Resuscitation, Volume 103, Pages 94-98, ISSN 0300-9572. https://pesquisa.bvsalud.org/portal/resource/pt/mdl-26980348.

Pulze, G., Alves, W. S., \& Paiva, B. C., \& Ferretti-Rebustini, R. E. L. (2019). Incidência e fatores associados à parada cardiorrespiratória nas primeiras 24 horas de internação em Unidades de Terapia Intensiva. Revista da Sociedade de Cardiologia do Estado de São Paulo. $29.192-196$. https://pesquisa.bvsalud.org/portal/resource/pt/biblio-1009728.

Rasia, M. A. (2016). Cuidados de enfermagem a pacientes em pós-parada cardiorrespiratória internados em Unidade de Terapia Intensiva: construção e validação de protocolo (tese). Repositório da UFSC. https://repositorio.ufsc.br/handle/123456789/167744. 
Research, Society and Development, v. 10, n. 12, e377101220475, 2021

(CC BY 4.0) | ISSN 2525-3409 | DOI: http://dx.doi.org/10.33448/rsd-v10i12.20475

Silva, R., Rodrigues, J. \& Nunes, N. (2017). Parada cardiorrespiratória e educação continuada em Unidade de Terapia Intensiva. Revista de Ciências Médicas. 25. 129. 10.24220/2318-0897v25n3a3391. https://pesquisa.bvsalud.org/portal/resource/pt/biblio-859891.

Sousa, L., Marques-Vieira, C., Severino, S. \& Antunes, V. (2017). Metodologia de Revisão Integrativa da Literatura em Enfermagem. Revista Investigação Enfermagem. 2, pp. 17-26. Coimbra. ISSN 2182-9764. http://www.sinaisvitais.pt/images/stories/Rie/RIE21.pdf\#page=17.

Zhou, D., Li, Z., Shi, G., \& Zhou, J. (2020). Proportion of time spent in blood glucose range 70 to $140 \mathrm{mg} / \mathrm{dL}$ is associated with increased survival in patients admitted to ICU after cardiac arrest, Medicina: Volume 99 - Edição 33 - p e21728. https://pesquisa.bvsalud.org/portal/resource/pt/mdl-32872055.

Zhuang, Y G., Chen, Y Z., Zhou, S Q., Peng, H u., Chen, Y Q., \& Li, D J. (2020). High plasma levels of pro-inflammatory factors interleukin-17 and interleukin23 are associated with poor outcome of cardiac-arrest patients: a single center experience. BMC Cardiovasc Disord 20, 170. https://pesquisa.bvsalud.org/portal/resource/pt/mdl-32293300. 